\title{
Sociocultural Learning in Globally Distributed Teams: An Exploratory Study
}

\author{
Douglas R. Vogel \\ City University of Hong Kong, \\ Hong Kong \\ isdoug@ityu.edu.hk \\ Ronnie H. Shroff \\ City University of Hong Kong, \\ Hong Kong \\ isronnie@cityu.edu.hk
}

\author{
Robert M. Davison \\ City University of Hong Kong, \\ Hong Kong \\ istobert@cityu.edu.hk \\ Sajda Qureshi \\ Erasmus University, The Netherlands \\ squreshi@fac.fbk.eur.n
}

\begin{abstract}
Characteristics of the new millennium suggest that we give students the experience of working in multi-cultural distributed teams to prepare them for present and future organizational demands. In general, students respond positively to this type of learning activity. However, we know little in terms of what they are really learning, how to improve the environment in which that learning takes place and how to assess the improvements, if any. In this paper we use tenets of the sociocultural learning model to explore aspects of learning in culturally differentiated teams distributed on two continents, using groupware for project support. We conclude that learning is taking place in a number of ways that makes relevant use of multi-cultural distributed teams and that our measurement instrument provides an initial basis for comparison across classes and technologies to assess whether we are improving the learning environment.
\end{abstract}

Keywords: sociocultural learning; distributed teams; groupware.

\section{Introduction}

In educational contexts, we seek to prepare students for present and future organizational demands. Characteristics of the new millennium suggest we give students the experience of working in multi-cultural distributed teams that cross disciplinary and national boundaries. In these learning environments, we are interested in how students from different cultures can work together effectively, not by establishing a common ground or adopting a particular culture, but by accommodating each other's culture in a synergistic fashion.

The sociocultural learning model has an especially good fit with attributes of multi-cultural distributed learning.

Material published as part of this proceedings, either on-line or in print, is copyrighted by the author with permission granted to the publisher of Informing Science for this printing. Permission to make digital or paper copy of part or all of these works for personal or classroom use is granted without fee provided that the copies are not made or distributed for profit or commercial advantage AND that copies 1) bear this notice in full and 2) give the full citation on the first page. It is permissible to abstract these works so long as credit is given. To copy in all other cases or to republish or to post on a server or to redistribute to lists requires specific permission from the author.
O'Loughlin (1992) cautions that the acquisition of knowledge should not be dissociated from the historical and cultural background of the learner. Therefore, it is important that students begin to construct meaning on their own terms and in their own interests, within their own culture. It is important that majority cultures should not force minority cultures into a common understanding; rather, cultures should be respected and allowed to co-exist in the context of shared activities. This presents the opportunity for synergy that can be lost through the dominance of any particular culture.

Technology in general and groupware in particular provide a way to bridge distance without physically disrupting people and potentially enable synergy to emerge. We have a variety of collaborative technologies that have been shown to enable such experiences in classroom settings (e.g, Alavi et al., 1997). As we explore the nature of distributed, sociocultural learning, a number of questions arise. Does sociocultural learning occur? What else occurs (or does not occur)? Can currently available technology stand up to the task? What are the changing roles (if any) 


\section{Sociocultural Learning}

of the instructor? Can we tell over time whether improvement is occurring. And finally, is it worth the effort?

In this paper we use tenets of the sociocultural learning model to examine aspects of learning in distributed team contexts. In the first instance, we use groupware technology to support teams of students from a single culture. In the second instance, we use the same technology and project structure but with students from two distinct cultures located on two continents.

\section{Background}

If we view culture in a broad sense as patterned ways of thinking, feeling and reacting, it is clear that distributed teams may be influenced by a number of perspectives. At the same time, we recognize that aspects of national, professional and corporate culture may emerge as teams interact to solve problems. The impact of culture will become an increasingly important issue as multi-cultural teams become more commonplace. Culture has been studied from various perspectives. For example, the work of Hofstede (1991) has been widely circulated while Erez and Earley (1993) have extensively explored dimensions of culture in a variety of contexts.

The sociocultural learning model provides a backdrop against which to create an environment and explore the implications of team interactions. The root of the sociocultural model is centered around the writings of Vygotsky (1978, 1986). As Leidner and Jarvenpaa (1995) note, "the sociocultural model is both an extension of and a reaction against some assumptions of constructivism". Like constuctivism (e.g., Piaget, 1973), the sociocultural model recognizes knowledge as created (constructed) by each learner. However, rather than assuming, as does Piaget (1973), that the goal of learning is the formation of abstract concepts to represent reality, socioculturalists feel that knowledge cannot be dissociated from the historical and cultural background of the learner (O'Loughlin, 1992).

Many other researchers and scholars have disseminated their own research findings and documented theoretical foundations, pedagogical developments and instructional approaches to sociocultural learning building upon the work of Vygotsky $(1978,1986)$. For example, Wertsch (1991) argues that the means that we bring to bear in communicating and interpreting our experiences are necessarily culturally constituted. Reasoning is conceived to be an inherently social and cultural process of meaning making. Meaning making is not viewed as an isolated mental activity but as a joint product of the person and the mediating means, operating in a particular setting (O'Loughlin, 1992). The theoretical framework used in this study reflects upon the different adaptations, viewpoints and principles as they apply in an electronic environment. A set of ten constructs emerges upon examination of the sociocultural literature (see Appendix A 4.

- Mediation: Social and individual psychological activity is influenced or mediated by the tools and signs in one's sociocultural milieu (e.g., written language, maps, artwork, diagrams, computer screens, etc.).

- Zones of Proximal Development refers to the distance between actual or independent problem solving and performance when provided with learning assistance from adults or more capable peers.

- Internalization is the process of taking new information that was experienced or learned within a social context and developing the necessary skills or intellectual functions to independently apply the new knowledge and strategies.

- Cognitive Apprenticeship refers to a socially interactive relationship and assumes that newcomer learners should be acculturated into an established community of practice by observing and participating on the periphery.

- Assisted Learning: Because learning precedes development, effective instruction can provoke developmental growth or rouse new skills to life. Teachers play a vital role in creating learning environments rich in meaning making and social negotiation activities.

- Teleapprenticeship: There is a myriad of online learning environments that are mediated by experts, peers, mentors and teachers, to help learners and teachers build and share knowledge through access to specialized expertise and information.

- Scaffolded Learning relates to the various forms of support or assistance provided to a learner by an expert or more capable peer that enables the learner to com-

\footnotetext{
${ }^{1}$ The extensive appendices are accessible on the web at http://www.cityu.edu.hk/is/staff/rd-app.pdf
} 


\section{Vogel, Davison, Shroff and Qureshi}

plete a task or solve a problem that would not have been possible without such support.

- Intersubjectivity refers to a temporary shared collective reality among individuals. Conferencing and collaborative technologies can foster such shared space or situational understanding between learning participants that can help them negotiate meaning, design new knowledge, and develop multiple problem-solving perspectives.

- Activity Setting as Unit of Analysis: Sociocultural theorists argue that the proper unit of analysis for research should be the activity or word meaning. Specific circumstances of an event or activity are essential to understanding how people act in their attempt to reach their goals.

- Distributed Intelligence in a Learning Community: Participation in a classroom is no longer didactic or transmissive, but a sophisticated instructional conversation. Not only technology, but a variety of other resources can be utilized in the learning community, e.g.: experts, mentors, peers, teachers, self-reflection and assessment.

If, as Vygotsky (1978) contended, student learning and development cannot be understood without reference to the social context, then it becomes essential to study the role of technology in a distributed environment. Such technology might offer new channels of communication and apprenticeship among students and learning participants of different cultural backgrounds, ability levels, and areas of expertise (Lave \& Wenger, 1993). In fact, technology has been widely used to support a constructivist perspective of education (Jonassen et al., 1999), and the use of collaborative technology to assist learning in classroom contexts (e.g. Alavi, 1994) and to link classes together, whether within a country (e.g., Alavi et al., 1997) or between countries (e.g. Jarvenpaa and Leidner, 1998) is increasingly common.

Groupware has much to offer in the context of distributed team support. In general, Group Support Systems (GSS) seek to minimize potential process losses and maximize process gains. For example, process losses can include: language difficulties, apprehension, failure to remember, conformance pressure, domination and information overload. Process gains, on the other hand, can include: synergy, more robust evaluation, stimulation, buy-in and cultural learning (Nunamaker, et al., 1991). When teams are distributed, it becomes easier for individual cultures to remain intact and let technological support enable sharing and communicating. When appropriately configured in support of appropriate processes with minimal critical structure, collaborative technology can enable multicultural teams achieve synergy. GSS, for example, are recognised as positively affecting knowledge acquisition (Kwok and Khalifa, 1998) and have been suggested to help combat "groupthink" (cf. Janis, 1972).

\section{Research Approach}

\section{Subjects and Setting}

In the first task, the Hong Kong participants were 21 part time students with full time jobs as middle managers. The Global Accounting Information Systems course (IS5101) was offered to students at the City University of Hong Kong pursuing a Master of Arts in International Accounting. The main objective of this course was to introduce students to the concept of Information Systems in organizations and global contexts with emphasis on accounting information system planning, application, evaluation and control.

The second task, which commenced six weeks later, linked the 21 students from the IS5101 class in Hong Kong with 104 students from Erasmus University in Rotterdam, the Netherlands. The Dutch participants were all full time upper level undergraduate students in Information Management. Their "Advanced Topics" course focused on managing information in organizations through the use of Information and Communications Technology (ICT). Its aim was to provide a working knowledge of the technological and organizational value of information systems. It is important to note that both groups of students used English as a second or third language.

\section{Technology, Task and Procedure}

An online, web-based groupware (eRoom) (http://www.instinctive.com) was utilized to support students in their tasks. eRoom allowed students to work together at any time and in any place (e.g. chatting and brainstorming, making a group decision or voting, arranging and organizing meetings, keeping track and sharing of group's files). Each team had a private team space as well as the opportunity to visit common spaces (e.g., the information resource center). 


\section{Sociocultural Learning}

In the first task, the students were given a scenario concerning the paper-based billing process used by a local accounting firm. The students, working in groups of three, were told that they had to devise an action plan for the reengineering and web-enabling of the billing process, presenting this action plan as a power point presentation for their boss - the CFO. The purpose of the project was to allow students an opportunity to share their knowledge and to constructively critique each other's work improvements and new insights. There were two objectives for this exercise: (1) to give students the opportunity to apply a groupware application to their course; (2) to give students an opportunity for collaborative interpretation and critical reflection on their coursework.

In the second task, each Hong Kong student was teamed with five Dutch students. Each of the 21 teams was given a task relating to the way in which teams function in a virtual organization drawn from a published list of important items related to managing IT in a global context (Tractinsky and Jarvenpaa, 1995). The students needed to discuss the task using the eRoom software tools, adapting their use of the tool to incorporate any activities that they wished to perform, e.g. brainstorming, polling, consensus formation, etc. Each group needed to produce a set of critical success factors (CSFs) for the virtual organization for their particular task.

\section{Instrument Development and Data Collection}

The questionnaire developed in this study (see Appendices) had 52 items that contributed to the 10 constructs. The instrument was administered to the students using a webbased GroupSystems survey. Sources of data included questionnaires and electronic transcripts captured in eRoom as well as open-ended student input and interaction observation (Table 1).

Observational recording of the dynamics of group work was aimed at understanding the perspectives, attitudes and experiences of the respondents and gaining a vicarious understanding of the participants' online tasks and interaction. Examples of eRoom documents used in this study were (1) messages posted by instructors; (2) entries posted by students; (3) messages between students and instructors; (4) the summaries of meetings in the eRoom discussion area.

\section{Results}

The questionnaire used in this study was developed from several sources, including instruments developed by other researchers and the sociocultural literature (see Appendix A). Content validity was addressed by drawing representative questions from a universal pool (Kerlinger, 1978).

Discriminant validity was addressed by examining how the

Table 1: Data Collection Procedures

\begin{tabular}{lll}
\hline Observations & Questionnaires & Documents \\
\hline Participants: & Participants: & ERoom Notes: \\
\hline - Students (Hong Kong) & Task 1 & - Action Plans \\
& - Students & - Work space discus- \\
& (Hong Kong) & sion \\
\hline - Students (Hong Kong) & Task 2 & - Critical Success Fac- \\
& - Students (Hong & - Pors \\
- Students (Netherlands) & Kong) & - Poll results \\
& - Students (Neth- & Work space discus- \\
& erlands) & sion \\
& & Information Resource \\
& & Center feedback \\
\hline
\end{tabular}




\section{Vogel, Davison, Shroff and Qureshi}

items underlying each construct loaded on different factors (cf. Weiss, 1970). Ninety nine of the 125 students responded to our questionnaire (79\%). For the 41 items retained in the instrument (see Appendix B), an itemrespondent ratio of 1:2.2 was achieved lying between 1:2 (Guilford, 1954) and 1:10 (Nunnally, 1978). To test the construct validity of items in the instrument, confirmatory factor analysis was performed and reliability of constructs assessed using Cronbach's (1951) alpha. The reliability levels of the constructs vary from 0.48 to 0.80 . All ten constructs that we proposed have been validated with factor analysis but, in some cases, individual items were thrown out as they did not have loadings above the 0.5 level that we employed (see Appendix B for the instrument items, together with factor loadings, alphas and eigenvalues).

In order to explore the results in a concise fashion, we have selected 12 of the 41 retained instrument items and propose to discuss how these items relate to the quality of work (an outcome measure) that students produced. The 12 items detailed in Table 2 were selected as they have a high level of congruence with the coursework objectives.

Considering the responses in aggregate, the students had a rather mixed perception of the eRoom environment and associated learning structures. $50 \%$ to $80 \%$ of students agreed or strongly agreed with eight of the items, but at the same time, a considerable minority (15\%-45\%) expressed neutral views. Fully $80 \%$ of students agreed that learning is more effective when they discover it for themselves (C5) - lending support to theories of constructivism - rather than being shown what to do, and $65 \%$ agreed that we achieved an appropriate balance of control over task components and processes $(\mathrm{C} 2)$, ensuring that students were increasingly responsible for their own communication and learning. Related to these two items, $61 \%$ agreed that they managed to help one another in solving project-related problems (Z4). Disagreement was generally muted, but two exceptions stand out. $61 \%$ of students indicated disagreement that online discussion provided a better environment for open communication compared with face to face discussion (T3), suggesting that the inconvenience of communicating across a six-hour time difference was considerable and that it was little ameliorated by the use of eRoom. Similarly, 32\% of students disagreed that eRoom's strucure was adequate to facilitate an environment conducive to in-depth discussion (S3) - again, a reaction against the dispersed mode of communication that was imposed on the students.
If we look at the responses of the students from the six teams whose coursework was rated most highly (A or A+), and further break down by country, additional findings emerge. For the Hong Kong team members, the responses tend to be positive, with minimal disagreement. It is interesting to note, for example that the HK students had a markedly lower level of agreement (43\%) with the suggestion that learning is more effective if done by oneself, rather than being shown what to do (C5) - compared with the responses as a whole (80\%) and compared to their Dutch team members (85\%). This is likely to be a product of the HK educational system, which has traditionally emphasized rote learning and memorization - such ingrained values die hard!

Both the Hong Kong students (86\%) and the Dutch students $(55 \%)$ made a reasonably strong recommendation for other distributed teams to use eRoom in the future (T5). Hong Kong (72\%) and Dutch (70\%) students equally agreed that they had helped one another in solving project related problems (Z4) - indicating that the successful teams did communicate effectively through eRoom, despite any misgivings they may have had with the software. A major difference lies in the question of whether or not the projects were sufficiently structured for the students to communicate effectively through eRoom (AS1). While the Hong Kong students indicated unanimous (100\%) agreement, only $35 \%$ of the Dutch students had this perception and $45 \%$ disagreed.

Allied to this finding is the question of whether online discussion provided a better environment for open communication than face-to-face discussion (T3). Fully $76 \%$ of the Dutch students disagreed with the suggestion, only $18 \%$ agreeing, whereas $43 \%$ of the Hong Kong students agreed and $57 \%$ were neutral. Such a polarized response may be indicative of significantly different expectations, though $60 \%$ of the Dutch students agreed that team members were able to communicate effectively with eRoom (D4).

\section{Discussion}

Our discussion reflects a combination of observational data, survey results and examination and assessment of project process interactions and output.

\section{Impact on the Students}

In general the students reacted positively to the use of technology and the opportunity to interact internationally. 


\section{Sociocultural Learning}

Their enthusiasm and curiosity combined to create an openness that yielded co-operation and encouraged higher levels of activity than typically encountered in class projects. The projects provided a high degree of realism and relevance, and the technology enabled a meeting space noted that "eRoom activities which allow discussion at any time and place with members with different culture and thinking" were particularly effective. Hong Kong students rated this project (Task Two in our study) as the highest of nine course activities while use of eRoom in exclusively

Table 2: Agree-Disagree Scores (All scores are rounded \%)

\begin{tabular}{|c|c|c|c|c|c|c|c|c|c|c|}
\hline & \multirow{3}{*}{ Questions } & & & & \multicolumn{6}{|c|}{ Members of Top 6 Teams } \\
\hline & & \multicolumn{3}{|c|}{ All Students } & \multicolumn{3}{|c|}{ Hong Kong } & \multicolumn{3}{|c|}{ Netherlands } \\
\hline & & $A^{*}$ & $N$ & $D$ & $A$ & $N$ & $D$ & $A$ & $N$ & $D$ \\
\hline M5 & $\begin{array}{l}\text { Routing (moving documents through a pre-defined approval } \\
\text { cycle) was an important function that strengthened the qual- } \\
\text { ity of the Critical Success Factors developed. }\end{array}$ & 48 & 45 & 7 & 29 & 71 & 0 & 53 & 47 & 0 \\
\hline $\mathbf{Z 4}$ & $\begin{array}{l}\text { We managed to help each other in solving problems related } \\
\text { to the project. }\end{array}$ & 61 & 22 & 17 & 72 & 14 & 14 & 70 & 15 & 15 \\
\hline IN5 & $\begin{array}{l}\text { The eRoom project helped me to effectively identify gaps in } \\
\text { my understanding and adapt to changes in the environment. }\end{array}$ & 35 & 39 & 26 & 57 & 43 & 0 & 32 & 32 & 26 \\
\hline $\mathrm{C} 2$ & $\begin{array}{l}\text { The balance of control over task components and processes } \\
\text { ensured that students were increasingly responsible for their } \\
\text { own communication and learning. }\end{array}$ & 65 & 28 & 7 & 86 & 14 & 0 & 74 & 10 & 16 \\
\hline C5 & $\begin{array}{l}\text { Learning is more effective if we discover it for ourselves, } \\
\text { rather than being shown what to do. }\end{array}$ & 80 & 15 & 5 & 43 & 43 & 14 & 85 & 15 & 0 \\
\hline AL4 & $\begin{array}{l}\text { Effective classroom instruction helped us to develop our } \\
\text { cognitive skills and see different aspects of an issue. }\end{array}$ & 58 & 28 & 14 & 86 & 14 & 0 & 50 & 33 & 17 \\
\hline T3 & $\begin{array}{l}\text { Online discussion provided a better environment for open } \\
\text { communication compared to face-to-face discussion. }\end{array}$ & 17 & 22 & 61 & 43 & 57 & 0 & 18 & 6 & 76 \\
\hline T5 & $\begin{array}{l}\text { I recommend the use of eRoom for other distributed project } \\
\text { teams? }\end{array}$ & 55 & 31 & 14 & 86 & 14 & 0 & 55 & 35 & 10 \\
\hline S3 & $\begin{array}{l}\text { The structure provided in eRoom was adequate to facilitate } \\
\text { an environment conducive to in-depth discussion. }\end{array}$ & 39 & 29 & 32 & 43 & 57 & 0 & 37 & 37 & 26 \\
\hline IJ5 & $\begin{array}{l}\text { The eRoom project helped me to utilise prior knowledge to } \\
\text { understand new experiences and apply course experiences } \\
\text { to build new knowledge. }\end{array}$ & 57 & 33 & 10 & 100 & 0 & 0 & 63 & 32 & 5 \\
\hline AS1 & $\begin{array}{l}\text { The project was adequately structured for us to communi- } \\
\text { cate effectively through eRoom. }\end{array}$ & 50 & 19 & 31 & 100 & 0 & 0 & 35 & 20 & 45 \\
\hline D4 & $\begin{array}{l}\text { Team members were able to collaborate effectively using } \\
\text { eRoom. }\end{array}$ & 58 & 27 & 15 & 86 & 14 & 0 & 60 & 25 & 15 \\
\hline
\end{tabular}

* A = Agree D = Disagree; $\mathrm{N}=$ Neutral 
The students did, however, experience difficulties. Differences in study background created confusion for the teams when attempting to achieve a shared agreement on issues relating to the research questions. As one student noted, "I found that my team members were rather rude and impolite and hoped that they were not typical" while another noted "people speak English but not necessarily know what the others mean". The timing of interactions between the two locations, for instance, caused much confusion and frustration. As one student noted "it was frustrated when no response was received from the teammates". The problems were compounded by students tending to work from home, office and the university, thus limiting the opportunity for synchronous interaction.

Considering what students really learned, we are certain that they experienced the ups and downs of the technology (e.g. "we can practically use the technology to complete a project and can assess the effectiveness and limitations of the technology based on this experience"), but that can be accomplished without linking half way around the world. Learning took place as students with various opinions were able to communicate with each other effectively to bring about a diversity of knowledge as suggested by Huber (1991). Thus, students changed from being passive recipients of knowledge to active participants in their own learning.

A high value added learning component revolved around experimentation with tools and establishment of communication protocols. Students displayed a collaborative spirit in trying tools in unconventional ways and discovered unique approaches to take advantage of the tools to solve problems. Furthermore, parallel communication in a computer-mediated environment helped encourage more contribution and participation from the quieter students. As we scrutinise construct items, we see positive indications that sociocultural learning, that would not exist in the absence of multi-cultural distributed collaboration, is occurring.

\section{Impact on the Instructors}

In this project, we too experienced curiosity in our exploration of a new area, and enjoyed facilitating activities for students who openly expressed their satisfaction with the process. Such an environment enables us to bring other perspectives into the classroom and engage in activities that truly add educational value to instructors as well as students. The richness of interaction and diversity of perspectives crossing national borders is far greater than that achieved in traditional classrooms or in achieved in traditional classrooms or in discussions with colleagues "down the corridor". Nevertheless, we experienced our share of difficulties, the technology not always performing as expected. Instructor roles also change. In international linkups, students learn from each other in a collaborative fashion with instructor facilitation. This can be advantageous and time saving (e.g., Johnson et al., 1991) in the sense of instructors not being at the center of conversations. However, facilitating in distributed classrooms requires significant process preparation with classes becoming less content focused and more dynamic (Aakhus et al., 1997).

\section{Is the Sociocultural Learning Model Useful?}

As we seek to learn from accumulated experience, we are trying to relate back to the theory, and so start to generate knowledge, not just recite success (or failure) stories. In this sense, the sociocultural learning model is useful, promoting a sustained focus that would otherwise be difficult to attain. To date we only have data from one linkedclassroom experience, making this the first, exploratory stage of a longitudinal study. Our objective is to initiate systematic comparison of technologies and cultural groups to assess whether improvement is really occurring in the nature of the learning environment. At this point, we suspect critical success factors are beginning to emerge based around the constructs identified in our instrument. Specifically:

- Mediation seems to bring to the fore issues associated with learning transformation;

- Zones of Proximal Development provides indicators of communication effectiveness over distance;

- Internalization gives a sense of knowledge application;

- Cognitive Apprenticeship illustrates self-directed learning;

- Assisted Learning aligns with facilitation;

- Teleapprenticeship indicates technology supported learning environment effectiveness;

- Scaffolded Learning relates to the impact of external structuring;

- Intersubjectivity gives an indication of synergy among team members; 


\section{Sociocultural Learning}

- Activity Setting as Unit of Analysis relates to activity setting comfort; and

- Distributed Intelligence in a Learning Community gives a sense of knowledge management.

As we refine the instrument further, it may be useful to move away from the somewhat opaque language of the sociocultural literature toward terms more easily identified by students and along the lines of the emerging critical success factors. Overall, we want to develop a sense of how to create an environment where learning is free to emerge without constraint but with minimal critical support and guidance.

\section{Study Limitations and Future Research}

Given the exploratory nature of this research, the limitations are many, not the least of which is the lack of a validated instrument. A further limitation involves application of the study to only a single linked class involving students predominantly from two cultures, some of whom were full time students, others being full time managers but part-time employees. Certainly, other interesting findings will emerge and challenge our work as we study additional cultures in various contexts. The whole nature and measurement of culture is also a limitation of the current study. We tried to apply Hofstede's VSM94 values survey (cf. Hofstede, 1991) but the results were so widely distributed within a supposedly bounded single culture that we feel that further investigation of societal culture is warranted. Indeed, we are still in search of a good instrument to measure the cultural dimensions of our student populations.

\section{Conclusion}

In this paper we use tenets of the sociocultural learning model to explore aspects of learning in multi-cultural teams distributed on two continents. We conclude that elements of sociocultural learning have indeed occurred. We have gained insights into the patterns of interaction among cross-cultural distributed groups. With respect to the students, we began to see elements of sociocultural learning emerge through the various ways in which they collaboratively used the tools and developed process protocols. Student learning continued throughout the project and enthusiasm remained high. From an instructor perspective, learning occurred as we created the environment for the students and began to see the broader implications of virtual team support. A new relationship between students and instructors emerges where the focus is involves knowledge construction, not information dissemination.

The overall question is whether it is worth the effort. It is usually easier to justify trying something once than making it an ongoing aspect of a course or program. Cost, coordination and operational use beyond a single instance requires consideration. Globally distributed team projects are difficult to sustain and require infrastructure support to leverage instructor input. Ma et al. (2000) point out a number of the organizational issues that need to be addressed. On the whole, however, we think that these types of activities present sufficient added value to students and instructors to warrant expansion and operationalization in educational programs. We feel also that the sociocultural learning model is a useful starting point for comparison of results across different cultures. Towards that end we expect to further refine our instrument and apply it routinely in our own courses.

\section{References}

Aakhus, M., Adkins, M., \& Glynn, M. (1997). Layers of learning: Facilitation in the distributed classroom. Proceedings of the $30^{\text {th }}$ Hawaii International Conference on System Sciences, CD-ROM version.

Alavi, M. (1994). Computer-mediated collaborative learning: An empirical evaluation. Management Inforation Systems Quarterly, 18(2), 159-174.

Alavi, M., Yoo, Y., \& Vogel, D. (1997). Using information technology to add value to management education. Academy of Management Journal, 40(6), 1310-1333.

Cronbach, L.J. (1951). Coefficient alpha and the internal structure of tests. Psychometrika, 16, 297-334.

Doise, W., \& Mugny, G. (1984). The social development of the intellect. Oxford: Pergamon Press.

Erez, M., \& Earley, P.C. (1993). Culture, self-identity and work. New York: Oxford University Press.

Guilford, J.P. (1954). Psychometric methods. New York: McGraw Hill.

Hofstede, G. (1991). Culture and organizations: Software of the mind. London: McGraw Hill.

Huber, G. (1991). Organization learning: An examination of the contributing process and the literatures. Organization Science, 2, 88115 .

Kerlinger, F.N. (1978). Foundations of behavioral research. New York: McGraw Hill. 
Janis, I.L. (1972). Victims of groupthink: A psychological study of foreign policy decisions and fiascoes. Boston: Houghton Mifflin.

Jarvenpaa, S., \& Leidner, D. (1998). Communications and trust in global virtual teams. Journal of Computer Mediated Communication, 3(4).

Johnson, D.W., Johnson, R.T., \& Smith, K.A. (1991). Cooperative learning: Increasing college faculty instructional productivity. Washington: George Washington University.

Jonassen, D., Peck, K., \& Wilson, B. (1999). Learning with technology: A constructivist perspective. Englewood Cliffs: Prentice Hall.

Kwok, C.W.R., \& Khalifa, M. (1998). Effect of GSS on knowledge acquisition. Information \& Management, 34(6), 307-315.

Lave, J., \& Wenger, E. (1993). Situated learning: Legitimate peripheral participation. New York: Cambridge University Press.

Leidner, D.E., \& Jarvenpaa, S.L. (1995). The use of information technology to enhance management school education: A theoretical view. Management Information Systems Quarterly, 19(3), 265-291.

Ma, L., Vogel, D., \& Wagner, C. (2000). Will virtual education initiatives succeed? Information Technology and Management, 1(4), 209-227.

Nunamaker, J.F., Dennis, A., Valacich, J., Vogel, D., \& George, J. (1991). Electronic meeting systems to support group work. Communications of the ACM, 34(7), 40 -61.

Nunnally, J.C. (1978). Psychometric Theory. New York: McGraw Hill.

O’Loughlin, M. (1972). Rethinking science education: Beyond Piagetian constructivism toward a sociocultural model of teaching and learning. Journal of Research in Science Teaching, 29(8), 791-820.

Piaget, J. (1973). To understand is to invent: The future of education. New York: Grossman.

Tractinsky, N., \& Jarvenpaa, S. (1995). Information systems design decisions in a global versus domestic context, Management Information Systems Quarterly, 19(4), 507-534.

Vygotsky, L. (1978). Mind in society: The development of higher psychological processes. Cambridge: Harvard University Press.

Vygotsky, L. (1986). Thought and language. Cambridge: MIT Press.

Weiss, D.J. (1970). Factor analysis in counselling research, Journal of Counselling Psychology, 17, 477-485.

Wertsch, J. (1991). Voices of the mind: A sociocultural approach to mediated action. Cambridge: Harvard University Press.

\section{Vogel, Davison, Shroff and Qureshi Biographies}

Douglas R. Vogel is Professor (Chair) of Information Systems at the City University of Hong Kong and formerly at the University of Arizona, USA. He received his Ph.D. in Business Administration from the University of Minnesota in 1986 where he was also research coordinator for the MIS Research Center. His research interests bridge the business and academic communities in addressing questions of the impact of management information systems on aspects of interpersonal communication, group problem solving, collaborative learning, and multi-cultural team productivity. He is especially active in introducing group support technology into enterprises and educational systems.

Robert Davison received his $\mathrm{PhD}$ from the City University of Hong Kong where he is currently an Assistant Professor of Information Systems. His research interests span the academic and business communities, examining the impact of GSS on group decision making and communication, particularly in cross-cultural settings. In recent years, Robert has co-organised minitracks at the Hawaii International Conference on Systems Science on Professional Ethics and Information Technology in Developing Countries. He is currently guest editing special issues of Communications of the ACM (Global Applications of Collaborative Technology) and IEEE Transactions on Engineering Management (Cultural Issues and IT Management). His work has appeared in the Information Systems Journal, Information \& Management, Group Decision \& Negotiation, Decision Support Systems, and the Communications of the ACM.

Ronnie Shroff is a doctoral student in the Department of Information Systems at the City University of Hong Kong. Ronnie's professional interests include the use of technology to support social-constructivist learning environments, collaborative learning, and effective learning environments. His other interests are in sociocultural theory, sociocultural instructional strategies and the development of cognitive learning skills and motivational dispositions. His work also focuses on how this development can be facilitated through interactive and learner-centered mediated instruction and the incorporation of instructional technology across teaching/learning settings.

Sajda Qureshi is an Assistant Professor at the Department of Decision and Information Sciences at the Faculty of Management at Erasmus University Rotterdam in the Netherlands. She holds a PhD in Information Systems from 


\section{Sociocultural Learning}

the London School of Economics and Political Science at the University of London in the United Kingdom. She has been coordinator of the Commonwealth Network of Information Technology for Development, she has lectured at the MIS Department of the University of Arizona in the USA and has been involved in various consultancy pro- jects in Italy and the UK. Her research interests include the use of electronic communication technologies to support coordination and decision making processes within international networks and network organisations and she has produced various publications in this area. 